Coulter R. \& van Ham M. (2013) Following people through time: An analysis of individual residential mobility biographies. Housing Studies 28(7), 1037-1055.

http://dx.doi.org/10.1080/02673037.2013.783903

\title{
Following people through time: An analysis of individual residential mobility biographies
}

\author{
Rory Coulter ${ }^{\mathrm{a}}$ \& Maarten van Ham ${ }^{\text {bcd }}$ \\ ${ }^{\text {a }}$ Department of Sociology, University of Cambridge, Cambridge, \\ UK \\ ${ }^{b}$ OTB Research Institute for the Built Environment, Delft \\ University of Technology, Delft, The Netherlands \\ ${ }^{\mathrm{c}}$ University of St Andrews, St Andrews, UK \\ d Institute for the Study of Labor (IZA), Bonn, Germany
}

\begin{abstract}
The life course framework guides us towards investigating how dynamic life course careers affect residential mobility decision-making and behaviour throughout long periods of individual lifetimes. However, most longitudinal studies linking mobility decision-making to subsequent moving behaviour focus only on year-to-year transitions. This study moves beyond this snapshot approach by analysing the long-term sequencing of moving desires and mobility behaviour within individual lives. Using novel techniques to visualise the desiremobility sequences of British Household Panel Survey respondents, the study demonstrates that revealing the meanings and significance of particular transitions in moving desires and mobility behaviour requires these transitions to be arranged into mobility biographies. The results highlight the oft-neglected importance of residential stability over the life course, uncovering groups of individuals persistently unable to act in accordance with their moving desires.
\end{abstract}

Key words: residential mobility; moving desires; life course; biography; longitudinal analysis

\section{Introduction}

Over the last few decades, research examining the residential mobility of households has been enriched by situating residential moves within the context of the life course (Clark \& Davies Withers, 2007). Within this framework, mobility is conceptualised as a mechanism which enables households to adjust their housing, neighbourhood and locational consumption to meet their changing needs and preferences (Clark \& Ledwith, 2006). Life events and gradual changes in the life courses of household members are understood to produce housing disequilibrium, thereby triggering the mobility decision-making process (Mulder \& Hooimeijer, 1999).

The initial reaction to disequilibrium is often conceptualised as the expression of a desire to move (Sell \& De Jong, 1983). Over time, moving desires can be succeeded by an expectation of moving and an eventual move response, providing that the individual is not restricted or constrained by household or macro-contextual factors (Coulter et al., 2011). A recent and growing literature has begun to investigate this decision-making process, linking individuals' expressed pre-move thoughts at year $t$ to their subsequent moving behaviour at 
t+x (Coulter et al., 2011; De Groot et al., 2011; Lu, 1999; Watkins et al., 2012). These studies have enhanced our understanding of which individuals act in accordance with their prior desires, intentions and expectations of moving.

Yet although this literature makes use of longitudinal data, focusing only on year-toyear 'snapshots' of individual lives neglects key components of life course theory. Fundamentally, life course theory conceptualises individual lives as long-term biographies, which are structured by the occurrence, timing and ordering of interlinked life events (Elder, 1994; Feijten, 2005). This perspective resonates with theories of mobility decision-making, which highlight the importance of situating moving decisions within biographical and structural contexts (Halfacree \& Boyle, 1993). Taken together, these insights suggest that it is valuable to link moving desires to subsequent moving behaviour across longer periods of individual lives than has previously been attempted. Such an analysis will allow us to distinguish those people whose moving desires are ephemeral from those who persistently desire to relocate. Making this distinction is important for both analysts and policymakers, as spending long periods of time desiring to move is likely to be detrimental for psychological well-being. Equally, evaluating the success of government attempts to promote housing choice (see HM Government, 2011) requires understanding how quickly individuals are able to 'reveal' their stated housing preferences through relocation. This is particularly important in the current economic climate, as policy, public and media discourse frequently highlight the structural constraints impeding residential mobility in contemporary Britain.

This paper is one of the first to analyse the long-term desire-mobility biographies of individuals. Investigating the ordering of pre-move thoughts and subsequent mobility across individual life courses requires adjusting our analytical framework. Analysing how moving desires and mobility behaviour are sequenced implies a shift away from exploring variation between individuals, towards an emphasis on variation over time within each person (Aisenbrey \& Fasang, 2010). This focus on desire-behaviour sequences extends our knowledge of mobility decision-making in two principal ways. Firstly, just as individual photographs gain greater meaning when ordered and compiled into albums, so the meanings and significance of experiencing (un)desired (im)mobility may become more apparent when located within the long-term biographies of individuals (see Gershuny et al., 1994). The meaning of experiencing an (un)desired move may, for example, only become apparent when it is known whether and for how long a person is subsequently content in their new location.

A second benefit of analysing desire-mobility sequences is that this approach can help develop our understanding of how individuals experience and react to housing disequilibrium over the life course. A variety of factors can inhibit people from relocating, even if they report that moving is desirable. For some people, intangible factors such as life aspirations, cultural values or social and kin networks may bind them to their current location, despite the tangible benefits which could be accrued elsewhere (Lundholm et al., 2004). Household resources and the macro-scale opportunity structures of regional housing and labour markets also condition whether an individual is able to make desired moves (Mulder \& Hooimeijer, 1999).

With this in mind, this study has two central aims. The first aim of the paper is to gain insight into individual mobility biographies by investigating how moving desires and actual moves are sequenced over individual life courses. Secondly, the study aims to develop our understanding of the links between mobility biographies and events occurring elsewhere in the life course. To address these aims, this study is one of the first to use prospectively gathered quantitative data to construct mobility biographies (see also Stovel and Bolan, 2004). Drawing upon a sample of British Household Panel Survey (BHPS) respondents tracked for up to 17 years, novel sequence analysis techniques and graphical plots are used to situate these mobility biographies within the wider context of life course trajectories. By tracking individuals over a long period of time, this study harnesses the full power of panel data. 


\section{Conceptual framework}

\section{Disequilibrium and the life course model}

It has been well documented that households relocate to reduce the disequilibrium generated when their housing supply and geographical location no longer meet their changing needs and preferences (Clark \& Ledwith, 2006). To conceptualise how disequilibrium is experienced, Brown \& Moore (1970) argued that living with disequilibrium produces housing 'stress'. When stress rises past an acceptable internally defined threshold, households begin to search for dwellings and neighbourhoods which they anticipate will better satisfy their new needs and preferences (Brown \& Moore, 1970).

A number of factors structure how households make moving decisions in response to housing stress. As it is costly to acquire the information necessary to conduct an effective housing search (particularly outside the local submarket), moving decisions are strongly constrained by the time and resources a household can devote to obtaining information (Brown and Moore, 1970). Hence, informational asymmetries between housing suppliers and searching households can condition relocation behaviour (Crook et al., 2012). In addition, how a household responds to housing stress may depend upon what is motivating them to consider moving. Many studies argue that most long-distance moves are made for educational and employment reasons (Böheim and Taylor, 2002; Lundholm et al., 2004), while people typically seek to make less costly shorter distance moves to adjust their housing or neighbourhood consumption (Mulder and Hooimeijer, 1999). Recent research has however begun to nuance this dichotomisation, emphasising the interlinked and heterogeneous factors driving residential moves (Boyle et al., 2009; Lundholm, 2007; Morrison and Clark, 2011).

Our understanding of how individuals and households experience and respond to the diverse causes of disequilibrium has been enhanced by situating analyses of residential mobility within the conceptual framework of the life course (Clark \& Davies Withers, 2007). Adopting a life course approach guides us to think of individual lives as unique biographies (Dykstra \& Van Wissen, 1999; Elder, 1994). Each individual biography is created by the life events a person experiences. Conceptually, life events can be grouped into separate household, housing, education and labour force 'life careers' (Mulder \& Hooimeijer, 1999). These careers run in parallel and are linked together, as events in one career can impact upon the trajectories of the other careers. As households can be thought of as networks of relationally 'linked lives' (Bailey et al., 2004), events in the lives of others can also influence individual biographies.

A key contribution provided by the life course model is the recognition that individual biographies are strongly conditioned by the sequence and contexts within which life events are experienced (Dykstra \& Van Wissen, 1999; Feijten, 2005). For example, childbirth can have different impacts on individuals depending on the age of the parents, the household structure within which the child is born, and whether the birth takes place before or after marriage. To understand an individual's present situation requires that we therefore also understand their past biography and life career trajectories (Elder, 1994).

\section{Residential mobility within a life course framework}

Many studies of residential mobility decision-making and behaviour adopt a life course approach, emphasising that events within the life careers of household members create disequilibrium and hence motivate relocation (Mulder \& Hooimeijer, 1999). These studies have shown that certain life events necessitate immediate residential moves, which may not be desired or anticipated (De Groot et al., 2011). Such events are often considered to 
constitute mobility triggers, as an individual has to move to resolve the sudden occurrence of disequilibrium (Michielin \& Mulder, 2008). For instance, forming or dissolving a partnership typically requires at least one partner to relocate (Feijten \& Van Ham, 2010). A large proportion of trigger events occur in the household careers of individuals, as educational and employment events usually trigger moves only if the event forces the individual to adjust their daily activity space (Mulder \& Hooimeijer, 1999).

As trigger events force rapid relocations, a year-to-year analytical framework seems at first glance to provide an appropriate way to investigate how these events are linked to mobility decision-making and behaviour. Yet ignoring the longer term life course biography within which these relocations occur may be problematic in two ways. Firstly, such an approach neglects the possibility of anticipatory effects, even though the anticipation of events such as marriage and childbirth has been linked to residential moves (Michielin \& Mulder, 2008). Secondly, failing to situate mobility within a long-term biographical context ignores the possibility that moves can have long lasting effects on future decision-making. This can happen because certain events constrain the immediate moving decisions of individuals, affecting their subsequent moving desires and behaviour. This could occur directly, for instance when an individual has to move to a certain location to form a partnership or to access a particular workplace.

Life events can also indirectly constrain the choice set accessible to a searching household. Unanticipated events necessitating immediate moves and events involving household changes may cause individuals to lack the time or resources to choose a new dwelling and location which meets their needs. Such moves may therefore actually create or perpetuate disequilibrium, necessitating subsequent adjustments in response to the moving desire this disequilibrium creates. For example, Feijten \& Van Ham (2010) show that separation and divorce often impact on mobility behaviour for several years after the dissolution event.

While disequilibrium can arise rapidly and directly trigger relocation, gradual changes in the life careers of individuals can also more incrementally produce housing stress and stimulate the decision to move (Mulder \& Hooimeijer, 1999). Rossi (1955) identified the changing space needs of individuals as they move through different household types as a key factor in this gradual production of housing stress. In Rossi's model, experiencing increasing housing stress triggers the desire to move to a more suitable dwelling and location (Brown \& Moore, 1970). This approach was extended by Speare et al. (1975), who argued that the link between housing stress and the desire to move is mediated by dissatisfaction. Influenced by these pioneering studies, a growing body of work has sought to investigate the links between mobility decision-making and subsequent moving behaviour. Several studies have examined both who desires to move and how these expressed moving desires affect the subsequent moving behaviour of households (Buck, 2000; Coulter et al., 2011; Ferriera \& Taylor, 2009; Landale \& Guest, 1985).

While an increasing number of studies are operationalizing life course theory by exploring intra-household dynamics in the expression and realisation of moving desires (eg. Coulter et al., 2012; Ferreira \& Taylor 2009), the biographical dimension of mobility decision-making has received far less attention (Halfacree \& Boyle, 1993). As few studies distinguish ephemeral from persistently expressed moving desires (Buck, 2000), comparatively little is known about how individuals perceive and experience gradual changes in housing stress over the life course. This is problematic in two principal ways. Firstly, disaggregating ephemeral from persistent moving desires may be crucial when evaluating how (not) acting in accordance with a moving desire can impact upon a person's well-being. For example, the effects of undesired immobility are likely to differ strongly depending upon whether a person has desired to move for one or for ten years. Secondly, focusing on mobility 
decision-making over long periods of time is valuable if we are to understand why people do not move, even though they may persistently wish to do so. Existing studies have shown that the ability to act upon a desire to move is heavily dependent upon the micro-context of the household (Buck, 2000; Coulter et al., 2011; Landale and Guest, 1985). Characteristics such as income, housing tenure and the caring, work and social ties of household members all condition how easily households are able to move when this is desired by one or more household members (Coulter et al., 2012). Macro-contextual factors such as the structure of labour and housing markets also constrain the choice set available to individuals desiring to relocate (Clark \& Dieleman, 1996).

Overall, the above discussion suggests that our understanding of residential mobility behaviour can be greatly enhanced by conducting a biographical analysis exploring the sequencing of moving desires and actual moves over individual life courses. Developing such an approach is the fundamental contribution of this paper.

\section{Data and methods}

\section{Data and sample selection}

In order to track the same individuals over a long period of time, this paper makes use of British Household Panel Survey (BHPS) data covering the years 1991-2007. The BHPS was initiated in 1991, when a nationally representative sample of over 10,000 adults from around 5,500 households was drawn from 250 postcode sectors across Great Britain (Taylor et al., 2010). These Original Sample Members (OSMs) completed interviews covering a wide range of topics and have been tracked and re-interviewed each subsequent year. New individuals could also enter the BHPS sample at each wave after the initial survey sweep. To ensure that all mobility biographies could be the same potential length, this study used only the records of OSMs first contacted in 1991. Due to the high risk of death truncating the histories of older respondents, the sample was further restricted to adult OSMs who were of working age (16 to 64 ) in 1991. This left a potential sample of 8,113 people. The records of these individuals were transformed into person-year format prior to analysis.

Each year, the BHPS has collected information on the moving desires of respondents. These were identified through the response given to the question 'If you could choose, would you stay here in your present home or would you prefer to move somewhere else?' This question guides individuals to express their moving desires rather than their moving intentions or plans, as respondents are directed to try and ignore any constraints which they think may prevent them from actually moving. A small number of individuals who replied that they 'did not know' whether they desired to move were treated as having no moving desire, as they appeared to have given moving little prior thought. Subsequent moving behaviour was then coded at each wave based upon whether the person was observed to have changed address between waves $t$ and $t+1$. This time gap was chosen to maximise the level of detail within each person's mobility biography, although it is worth noting that little can be known about rapid changes in desires between waves.

Constructing mobility biographies required information on moving desires and subsequent moving behaviour for each respondent at every survey sweep. Given the stringency of these requirements, it is unsurprising that participant attrition constrained the number of usable biographies. Participant attrition is common to almost all panel surveys and it poses a particular challenge for analysts if found to be selective (Taris, 2000). Preliminary bivariate and modelling analyses (results not shown here) suggested that younger OSMs, men, ethnic minorities, singles and OSMs with a low level of education were more likely to fail to provide information on moving desires and actual moving behaviour at all survey sweeps. We 
also anticipate that serial movers are less likely to provide complete mobility biographies, as the attrition of BHPS respondents is known to be associated with geographical mobility (Buck, 2000). These findings are in line with well-documented patterns of attrition in most panel surveys (Taris, 2000).

Two steps were taken to minimise the impact of this participant attrition. Firstly, simple longitudinal imputation was used to 'fill in' small gaps on the moving desire variable by making use of the moving desires the respondent reported at the previous and subsequent waves (full details of this procedure are available upon request). Secondly, we considered biographies to be complete if data on an individual's moving desires and subsequent moving behaviour were available for at least the first twelve consecutive waves of the survey. After constructing mobility biographies as outlined above, we were left with a sample of 4,912 individual biographies (61\% of eligible OSMs). Of these 4,912 biographies, $13 \%$ contain imputed cases. Further analysis demonstrated that excluding these imputed sequences from the analyses led to no substantive changes in the results. As attrition rates in the BHPS were highest in the first few waves of data collection (Taylor et al., 2010), a large proportion of excluded biographies were much too short to be usable, even with imputation.

\section{Methods}

By comparing an individual's expressed moving desire at time $t$ with their observed moving behaviour at $t+1$, an 'element variable' was then coded to categorise each person-year based upon the combination of moving desire and mobility behaviour reported at that year (Table 1). By tracking the ordering of this element variable across all the person-years provided by each respondent, it was then possible to create 4,912 individual sequences of moving desires and actual moving behaviour. These mobility biographies can be visualised as a series of 4,912 individual timelines which represent how each respondent moves through each of the states in Table 1 over time (see Figure 1). These timelines were plotted in Stata v.10.1 using a third party SQ-Ado bundle of Stata programs (Brzinsky-Fay et al. (2006) for full details). Visualising and analysing mobility sequences provides a useful alternative to event history analyses (Feijten, 2005), as studying sequences enables us to explore how particular transitions fit together in different ways to produce diverse long-term biographies (Aisenbrey and Fasang, 2010).

$$
\text { ***Table } 1 \text { about here*** }
$$

Within these plots, each horizontal line contains the mobility biography of an individual from 1991 onwards. The timeline is colour coded for each of the years the person was interviewed, based upon the combination of moving desire and subsequent behaviour observed at that survey sweep. Each category in Table 1 is therefore assigned a different colour and it is the sequence of states experienced by each individual which makes up their mobility biography. White lines at the end of sequences indicate that the person's biography was truncated by missing data. As all included OSMs had to provide at least twelve consecutive years of data on moving desires and subsequent moving behaviour, each respondent can have a maximum of 4 white years at the end of their sequence.

While the intra-household dimension of mobility decision-making has been the subject of a growing literature (Coulter et al., 2012; Ferreira \& Taylor, 2009), this paper does not investigate intra-household variation in the type of sequence experienced. Our focus on individual sequences rather than just one sequence per household seems justified, as individuals can move through many different household situations over a seventeen year 
period. In addition, prior research shows that intra-household disagreement over whether moving is desirable is common (Coulter et al., 2012; Ferreira \& Taylor, 2009). Hence it would be conceptually problematic to attempt to think of overall 'household histories', as each individual within each household experiences their own desire-mobility sequence across the study period.

\section{Analysis}

Most studies linking mobility decision-making to subsequent moving behaviour investigate the likelihood of individuals realising their pre-move thoughts across several waves of a longitudinal study (eg. De Groot et al., 2011; Lu, 1999; Watkins et al., 2012). Table 2 replicates this focus on wave-to-wave transitions for all pairs of person-years in the sample. The results hint that state dependence is common for stayers, as both desired and undesired stayers (people who desire to move but who do not immediately realise this desire) are most likely to remain in the same state across two consecutive survey waves. Mobility typically resolves disequilibrium, as the majority of (un)desired moves are followed by the individual becoming a desired stayer. Intriguingly, there are comparatively small differences in the subsequent states of individuals making desired and undesired moves.

*** Table 2 about here***

While informative, Table 2 does not enable us to investigate how these transitions are situated within the wider life course trajectories of individuals. For instance, we do not know whether the stability within the undesired stayer category is caused by a small number of individuals remaining undesired stayers for a long time, or whether many individuals experience short spells in this state. As a result, we can infer little about the meaning or long-term consequences of an individual experiencing a particular transition from this wave-to-wave approach. The meaning and consequences of remaining an undesired stayer over two waves is likely to be highly dependent upon the wider sequence of moving desires and mobility behaviour within which this experience is situated.

$* * *$ Figure 1 about here***

To focus upon individual mobility biographies, Figure 1 provides a visualisation of the sequences of moving desires and moving behaviour experienced by all 4,912 sample members after 1991. Each horizontal line represents the sequence of one individual, with the coloured blocks indicating the combination of moving desire and subsequent behaviour recorded at each survey wave (see Table 1). The figure shows that there are considerable regularities in the types of sequence experienced. Large numbers of individuals remain desired stayers for very long periods of time, while the steadily diminishing cones of undesired stayers indicates that many people also spend long periods harbouring a frustrated moving desire. This seems to validate Cooke's (2011) assertion that an empirical focus on immobility is important if we are to develop our understanding of the meaning and consequences of mobility.

The long blue tails (signifying spells as a desired stayer) visible after many move events in Figure 1 imply that moving is often a positive experience, meeting the needs and preferences of individuals. While it is also clear that many people have highly complex mobility biographies, overall the figure highlights the value of situating each transition within a longer-term context. This enables us to identify individuals for whom the same year-to-year transition may have widely differing meanings and implications. For example, while some 
people appear to remain undesired stayers for long periods of time, others oscillate in and out of this state or subsequently manage to become content after relocating.

By grouping all sequences into one plot, Figure 1 follows individuals across different stages of their life courses. As many studies show that the propensity to move varies systematically with age (Clark \& Dieleman, 1996), further analysis (not shown) was undertaken to explore the effects of subdividing the sequences presented in Figure 1 by the age of the respondent. This analysis showed that sequence stability increases with age, as a greater proportion of older people remain desired stayers for long periods of time. This increase in stability does not necessarily signify increased contentment however, as a larger proportion of older individuals appear also to remain as long-term undesired stayers. Unsurprisingly, as age rises the complexity and heterogeneity of sequences generally drops, although it is clear that individuals across the age brackets often experience similar sequences. This lack of an unambiguous relationship between age and mobility sequences demonstrates that cohorts may not share similar life trajectories. This highlights the difficulty of conceptualising housing careers as the outcome of a 'family life cycle', in which people progress through a common and linear sequence of household types and housing situations as they age (Rossi, 1955).

As life course theory explicitly aims to understand the diversity of life trajectories (Elder, 1994), studies investigating the sequencing of life events typically seek to classify the identified sequences into a typology (Clark et al., 2003; Pollock, 2007; Stovel \& Bolan, 2004). This often involves the use of optimal matching (OM) methods (Abbot \& Tsay, 2000; Aisenbrey \& Fasang, 2010). OM analyses involve choosing a cost scheme and then using algorithms to compute the 'distance' between all pairs of sequences (see Aisenbrey \& Fasang, 2010 for further explanation). These distances can then be used to group sequences using cluster analysis (Pollock, 2007). In this paper a series of theoretically informed rules are used to classify mobility sequences into groups. As with $\mathrm{OM}$ methods, this approach can be considered to be 'an empirically informed subjective decision' (Pollock, 2007: 171). We use rules because we want our groupings to have conceptual relevance, with individuals allocated to groups based upon the (non)observance of particular states and transitions in their sequences. Using these rules we identified eight types of mobility biography: the rooted, wishful thinkers (cf. Sell \& De Jong, 1983), contented movers, discontented movers, adaptive movers, oscillators, the highly mobile and miscellaneous. The identification rules and a description of the main group features are contained in Table 3.

$$
* * * \text { Table } 3 \text { about here*** }
$$

In order to visually represent the main features of these eight categories, Figures $2 \mathrm{a}$ and $2 \mathrm{~b}$ present plots of the individual sequences within each group. Overall, the plots demonstrate that there is a high degree of regularity in the types of sequence experienced by individuals. A large proportion of individuals never move (the rooted and wishful thinkers). Of those individuals who do move, many frequently make desired moves which seem to resolve their housing disequilibrium (contented movers). Comparatively few individuals consistently desire to move immediately after making previously (un)desired moves (discontented movers). Interestingly, many individuals do not appear to be disadvantaged by moving when this was not desired (adaptive movers). Relatively few individuals also repeatedly express and abandon moving desires (oscillators) or make multiple moves within the study period (highly mobile). While there is undoubtedly heterogeneity within each category, the plots demonstrate that there are also clear patterns in the long-term sequencing of moving desires and actual mobility behaviour over life courses. These regularities are difficult to detect without categorising and then visualising mobility biographies. 
The above figures deepen our understanding of the heterogeneous meanings and consequences of spending time in particular states. For instance, the meaning and significance of experiencing a spell as an undesired stayer clearly varies across the groups. While wishful thinkers consistently express a desire to move, the moving desires of oscillators are much more ephemeral. This may indicate that individuals in these two groups wish to move for different reasons. The meaning of experiencing a spell as a desired stayer also varies by group. For the rooted and for contented movers, such spells indicate contentment with the current dwelling and neighbourhood. In contrast, discontented movers and oscillators may experience spells as desired stayers after reluctantly abandoning an unattainable desire to move. For these individuals, spells as a desired stayer may indicate that the respondent has jettisoned their desire to move to reduce the cognitive dissonance induced by an inability to relocate.

Following individuals over a long period of time also deepens our understanding of the varied meanings and consequences of moving or experiencing transitions in state. While the desired moves of contented movers appear to satisfy their needs and preferences, making desired moves seems to be a less positive experience for discontented movers and for the highly mobile. These individuals often desire to relocate again immediately after moving. Similarly, making undesired moves can be both a positive and a disruptive event. Although adaptive movers do not appear disadvantaged by undesired moves, discontented movers typically wish to relocate again immediately after making an undesired move. These split experiences suggest that we observe two forms of undesired mobility. Individuals who do not appear disadvantaged by undesired moves may, in fact, have actually desired to move, although this remains unobservable because the desire was first expressed just before the move took place. Alternatively, such individuals could have come to accept that the benefits to be gained from moving outweighed the unwanted disruption of relocating. In contrast, individuals who are disadvantaged by an undesired move may have actively wished to stay in their current dwelling but have been forced out by exogenous circumstances, such as the demands of their partner's job or relationship dissolution. This complexity of meanings and experiences can only be observed if we track the desires and behaviour of individuals over long periods of time.

One of the main challenges for studies investigating the sequencing of life course careers has been to explain the patterns observed (Wu, 2000). Using sequence type as the dependent variable, we now analyse how the trajectories of other life course careers are associated with mobility biographies. As previous research and further analysis shows a clear link between age and mobility behaviour, Figure 3 displays the percentage of individuals in each age bracket (in 1991) experiencing each type of sequence. Broadly speaking, the expected patterns are evident. As age rises, the probability of an individual being rooted increases, while the likelihood of being a contented or discontented mover drops. Individuals over 30 in 1991 are unlikely to be highly mobile. Interestingly, 30-49 year olds are the most likely to be wishful thinkers. This may be because family and career ties to locations often peak at this stage in the life course. While the complexity of many youthful sequences means that young individuals are slightly over-represented in the miscellaneous category, the proportions from the two older age groups are fairly similar.

***Figure 3 about here*** 
To analyse how mobility biographies are linked to the wider trajectories of individual life courses, we now estimate a series of models which have sequence type as the dependent variable. This required the construction of a series of independent variables summarising the trajectory of each respondent's household, housing, education and socio-economic careers over the entire study period (Table 4). To avoid breaching the Independence of Irrelevant Alternatives assumption (IIA) of the multinomial logit model, we estimate a series of six separate logistic regression models. Each model analyses the propensity for individuals to experience a given sequence type (excluding miscellaneous sequences). The reference category for each model is contented movers. Contented movers are used as the reference category as we are interested in how the independent variables affect mobility experiences and not just moving propensities. In each model, a small number of individuals missing data on education level were removed. The Cox-Snell pseudo- $r^{2}$ values indicate that the models' explanatory power varies. While the rooted, discontented movers and the highly mobile are predicted well, the logit models for adaptive movers and oscillators fit poorly. This suggests that these categories are the least distinct, perhaps due to internal heterogeneity or because unobservable factors distinguish these respondents from contented movers.

$$
\begin{aligned}
& * * * \text { Table } 4 \text { about here } * * * \\
& * * * \text { Table } 5 \text { about here*** }
\end{aligned}
$$

Individuals are more likely to be rooted than contented movers if they are older, without children, homeowners or with a low income. Wishful thinkers appear quite similar, although both young and older individuals are less likely than those aged 30-49 to experience this type of sequence. This may be due to unobserved factors such as occupational ties. The strong negative effect of household income suggests that a lack of resources persistently hinders the realisation of moving desires. The likelihood of being discontented with moves appears to rise if the person is female, single or changes marital status. This latter result may indicate that further adjustments are needed to resolve the housing disequilibrium generated by household changes. A volatile income, perhaps associated with a fractured employment history, is also associated with discontentment, as is changing tenure (particularly exiting homeownership or having a complex housing career). Individuals are most likely to be adaptive rather than contented movers for similar reasons. These findings suggest that undesired moves can be both positive and negative experiences, as adaptive movers are more likely to be entering partnership or exiting homeownership.

Oscillators are poorly predicted by their model, although there is tentative evidence that individuals who are younger, gain children and those with higher incomes are less likely to oscillate than act successfully upon their moving desires. The highly mobile results are as expected. Older individuals and those with more stable life courses appear less likely to be highly mobile. Overall, the lack of significant education effects is unanticipated, although these effects may be captured by close associations between education and income. The results from the models clearly demonstrate the close links between mobility biographies and the trajectories of other life course careers.

\section{Conclusions}

This paper is one of the first to investigate how individuals express moving desires and experience residential mobility over long periods of time. Although many studies have adopted a life course framework when linking moving desires to subsequent moving 
behaviour, most empirical analyses have been based around the analysis of year-to-year transitions. This approach has yielded valuable insights, but only provides snap-shots of individual lives. This paper argues, in line with life course and migration theories (Dykstra \& Van Wissen, 1999; Halfacree and Boyle 1993), that the meanings and consequences of experiencing mobility events can be better understood when these are situated within life course biographies. This study therefore fits within a growing body of sociological literature seeking to empirically operationalise the concept of long-term life course trajectories (Abbott \& Tsay, 2000; Aisenbrey \& Fasang, 2010; Pollock, 2007; Stovel \& Bolan, 2004). Fundamentally, investigating mobility biographies enables us to link the empirical study of residential mobility more closely to pertinent theory.

Three sets of findings are of particular relevance for our understanding of mobility decision-making and moving behaviour. Firstly, the results highlight that the meanings and consequences of experiencing particular combinations of moving desire and behaviour will vary depending upon how these states and transitions are situated within wider biographies. Remaining an undesired stayer for fifteen years is likely to be a much more negative experience than desiring to move for two years before relocating. Equally, a long-term approach seems valuable if we are to understand the heterogeneous consequences of particular move events. While some individuals seem to adapt quickly to undesired moves, others are left unfulfilled by desired mobility. This suggests that resolving housing disequilibrium may often take a considerable period of time and multiple residential moves. Alternatively, some individuals may have such dynamic life careers that relocations are regularly desired. This heterogeneity of experiences is missed in year-to-year analyses. Further research modelling how a person's biographical experiences affect their later behaviours could therefore greatly improve our understanding of the residential mobility process (Rossi, 1955: 184).

Revealing the importance of long periods of immobility throughout the life course is the second key insight provided by an empirical examination of sequences. While wave-towave analyses implicitly privilege move events, the results of this study remind us that mobility (or even desiring to move) actually occurs relatively infrequently within individual life courses. After reaching age 30, immobility seems to be the norm for many individuals. Planning how to adapt to the increasing residential immobility generated by an ageing population may therefore be an important task for British policymakers. If people continue to become more likely to desire to stay in one place as they age, over time policies promoting housing choice are likely to increasingly conflict with policies aiming to 'get Britain moving' in order to both stimulate the housing market and promote labour market flexibility (see HM Government, 2011). As a result, both academic research and policy would benefit from greater analysis of why people do not move, especially when relocating may provide them with new opportunities (Cooke, 2011; Hanson, 2005).

An increased focus on long-term stability seems particularly pertinent as the results show that many immobile individuals want to move but are persistently unable to do so. This finding would seem to suggest that place attachment and social or kin ties cannot explain the immobility of many individuals, as we would expect these factors to inhibit people from even expressing a desire to move. By showing that many individuals who want to move do not go on to do so, the results indicate that researchers need to devote more attention to developing ways to integrate stated and revealed preference modelling of housing demand, perhaps through a greater use of longitudinal analysis (Watkins et al., 2012). Such work is especially pertinent given that the global financial crisis has increased the structural constraints faced by households seeking to move home.

Identifying and characterising persistently disadvantaged groups of wishful thinkers and discontented movers is this paper's final empirical contribution. The results show that low 
levels of income persistently prevent individuals from acting upon their moving desires, providing evidence that access to resources plays a central role in determining whether people are able to exercise effective housing choice. This could have implications for the psychological well-being of poorer individuals, who may be 'trapped' in dissatisfactory dwellings and neighbourhoods by their lack of financial resources. In contrast, the results also show that discontentment with mobility is associated with changes in household situation. There is also evidence that fluctuating incomes and changes in housing tenure (particularly exiting homeownership) are linked to negative experiences of moving. This may be because these life events trigger unwanted moves, which in turn produce further disequilibrium and dissatisfaction as individuals may lack either the resources or the time to select a desirable dwelling and neighbourhood.

Conceptually, the results show that it is valuable to adopt a biographical approach when studying mobility decision-making and behaviour. Peoples' pre-move thoughts and their moving behaviour at a given time point cannot be easily understood without some knowledge of their past experiences of (im)mobility. Although common in qualitative studies, the biographical framework adopted by this paper remains rare within the quantitative literature. While data constraints have traditionally inhibited work of this kind, the continuing investments many countries are making in panel and linked register datasets should enable further quantitative analysis of residential mobility and other life course biographies.

\section{References}

Abbott, A. \& Tsay, A. (2000) Sequence analysis and optimal matching methods in sociology, Sociological Methods \& Research, 29(1), pp. 3-33.

Aisenbrey, S. \& Fasang, A. (2010) New life for old ideas: The "second wave" of sequence analysis bringing the "course" back into the life course, Sociological Methods \& Research, 38(3), pp. 420-462.

Bailey, A. J., Blake, M. K. \& Cooke, T. J. (2004) Migration, care, and the linked lives of dual-earner households, Environment and Planning A, 36(9), 1617-1632.

Böheim, R. \& Taylor, M. (2002) Tied down or room to move? Investigating the relationships between housing tenure, employment status and residential mobility in Britain, Scottish Journal of Political Economy, 49(4), pp. 369-392.

Boyle, P., Feng, Z. \& Gayle, V. (2009) A new look at family migration and women's employment status, Journal of Marriage and Family, 71(2), pp. 417-431.

Brown, L. A. \& Moore, E. G. (1970) The intra-urban migration process: A perspective, Geografiska Annaler Series B, 52(1), pp. 1-13.

Brzinsky-Fay, C., Kohler, U. \& Luniak, M. (2006) Sequence analysis with Stata. Stata Journal, 6(4), pp. 435-460.

Buck, N. (2000) Using panel surveys to study migration and residential mobility, in: D. Rose (Ed.) Researching Social And Economic Change: The Uses Of Household Panel Studies, pp. 250-272 (London, Routledge). 
Clark, W. A. V. \& Davies Withers, S. (2007) Family migration and mobility sequences in the United States: Spatial mobility in the context of the life course, Demographic Research, 17(20), pp. 591-622.

Clark, W. A. V. \& Ledwith, V. (2006) Mobility, housing stress, and neighborhood contexts: Evidence from Los Angeles, Environment and Planning A, 38(6), pp. 1077-1093.

Clark, W. A. V., Deurloo, M. \& Dieleman, F. (2003) Housing careers in the United States, 1968-93: Modelling the sequencing of housing states, Urban Studies, 40(1), pp. 143-160.

Clark, W. A. V. \& Dieleman, F. (1996) Households And Housing: Choice And Outcomes In The Housing Market. (New Brunswick, Centre for Urban Policy Research).

Cooke, T. J. (2011) It is not just the economy: Declining migration and the rise of secular rootedness, Population, Space and Place, 17(3), pp. 193-203.

Coulter, R., van Ham, M. \& Feijten, P. (2012) Partner (dis)agreement on moving desires and the subsequent moving behaviour of couples, Population, Space and Place, 18(1), pp.16-30.

Coulter, R., van Ham, M. \& Feijten, P. (2011) A longitudinal analysis of moving desires, expectations and actual moving behaviour, Environment and Planning A, 43(11), pp. 27422760.

Crook, A. D. H., Ferrari, E. \& Kemp, P. A. (2012) Knowing the area: The management of market and business risks by private landlords in Scotland, Urban Studies, 49(15), pp. 33473363.

De Groot, C., Mulder, C., Das, M. \& Manting, D. (2011) Life events and the gap between intention to move and actual mobility, Environment and Planning A, 43(1), pp. 48-66.

Dykstra, P. A. \& van Wissen, L. J. G. (1999) Introduction: The life course approach as an interdisciplinary framework for population studies, in L. J. G. van Wissen \& P. A. Dykstra (Eds) Population Studies: An Interdisciplinary Focus, pp.1-22 (New York, Plenum Press).

Elder, G. H. (1994) Time, human agency and social change: Perspectives on the life course, Social Psychology Quarterly 57(1), pp. 4-15.

Feijten, P. \& van Ham, M. (2010) The impact of splitting up and divorce on housing careers in the UK, Housing Studies, 25(4), pp. 483 - 507.

Feijten, P. (2005) Life Events And The Housing Career: A Retrospective Analysis Of Timed Effects (Delft, Eburon).

Ferreira, P. \& Taylor, M. (2009) Residential mobility, mobility preferences and psychological health, in: M. Brynin \& J. Ermisch (Eds) Changing relationships, pp. 161-179 (Oxford, Routledge).

Gershuny, J., Rose, D., Scott, J. \& Buck, N. (1994) Introducing household panels, in: N. Buck, J. Gershuny, D. Rose \& J. Scott (Eds) Changing Households: The British Household Panel Survey 1990-1992, pp. 10-26 (Colchester, University of Essex). 
Halfacree, K. H. \& Boyle, P. J. The challenge facing migration research: The case for a biographical approach, Progress in Human Geography, 17(3), pp. 333-348.

Hanson, S. (2005) Perspectives on the geographic stability and mobility of people in cities, Proceedings of the National Academy of Sciences of the United States of America, 102(43), pp. 15301-15306.

Her Majesty's (HM) Government. (2011) Laying the Foundations: A Housing Strategy for England (London, Department for Communities and Local Government).

Landale, N. S. \& Guest, A. M. (1985) Constraints, satisfaction and residential mobility: Speare's model reconsidered, Demography, 22(2), pp. 199-222.

Lu, M. (1999) Do people move when they say they will? Inconsistencies in individual migration behavior, Population \& Environment, 20(5), pp. 467-488.

Lundholm, E. (2007) Are movers still the same? Characteristics of interregional migrants in Sweden 1970-2001, Tijdschrift voor Economische en Sociale Geografie, 98(3), pp. 336-348.

Lundholm, E., Garvill, J., Malmberg, G. \& Westin, K. (2004) Forced or free movers? The motives, voluntariness and selectivity of interregional migration in the Nordic countries, Population, Space and Place, 10(1), pp. 59-72.

Michielin, F. \& Mulder, C. (2008) Family events and the residential mobility of couples, Environment and Planning A, 40(11), pp. 2770-2790.

Morrison, P. S. \& Clark, W. A. V. (2011) Internal migration and employment: Macro flows and micro motives, Environment and Planning A, 43(8), pp. 1948-1964.

Mulder, C. \& Hooimeijer, P. (1999) Residential relocations in the life course: in L. J. G. van Wissen \& P. A. Dykstra (Eds) Population Studies: An Interdisciplinary Focus, pp. 159-186 (New York, Plenum Press).

Pollock, G. (2007) Holistic trajectories: A study of combined employment, housing and family careers by using multiple-sequence analysis, Journal of the Royal Statistical Society: Series A, 170(1), pp. 167-183.

Rossi, P. H. (1955). Why Families Move: A Study in the Social Psychology of Urban Residential Mobility (Glencoe, Free Press).

Sell R. G. \& De Jong G. (1983) Deciding whether to move: Mobility, wishful thinking and adjustment, Sociology \& Social Research, 67(2), pp. 146-165.

Speare, A., Goldstein, S. \& Frey, W. (1975) Residential Mobility, Migration, And Metropolitan Change (Cambridge, Ballinger Publishing).

Stovel, K. \& Bolan, M. (2004) Residential trajectories: using optimal alignment to reveal the structure of residential mobility, Sociological Methods \& Research, 32(4), pp. 559-598.

Taris, T. (2000) A Primer in Longitudinal Data Analysis (London, Sage). 
Taylor, M. F. (Ed) with Brice, J., Buck, N. \& Prentice-Lane, E. (2010) British Household Panel Survey User Manual Volume A: Introduction, Technical Report and Appendices (Colchester, University of Essex).

Watkins, C., Ferrari, E., Leahy Laughlin, D., Aldridge, M. \& White, M. (2012) Household Mobility Expectations and Estimates of Local Housing Demand. A report for Royal Institution of Chartered Surveyors (London, RICS).

Wu, L. (2000) Some comments on "Sequence analysis and optimal matching methods in sociology: Review and prospect”, Sociological Methods \& Research, 29(1), pp. 41-64. 
Figures and Tables

Table 1. Combinations of moving desire and subsequent moving behaviour

\begin{tabular}{lll}
\hline Moving desire at wave $\boldsymbol{t}$ & \multicolumn{2}{|c}{ Actual moving behaviour between waves $\boldsymbol{t}$ and $\boldsymbol{t}+\boldsymbol{1}$} \\
\cline { 2 - 3 } & No move & Move \\
\hline No desire & Desired stayer & Undesired mover \\
Desire & Undesired stayer & Desired mover \\
\hline
\end{tabular}


Table 2. Moving desires and subsequent moving behaviour across two consecutive survey waves

\begin{tabular}{|c|c|c|c|c|c|}
\hline \multirow{2}{*}{$\begin{array}{l}\text { Moving desire and subsequent } \\
\text { moving behaviour at } t\end{array}$} & \multicolumn{4}{|c|}{ Moving desire and subsequent moving behaviour at $t+1$} & \multirow{2}{*}{$\begin{array}{c}\text { Total } \\
(100 \% \text { and } N)\end{array}$} \\
\hline & Desired stayer & Undesired stayer & Undesired mover & Desired mover & \\
\hline Desired stayer & 83.23 & 11.81 & 2.88 & 2.08 & 44,715 \\
\hline Undesired mover & 57.50 & 16.63 & 11.06 & 14.81 & 2,026 \\
\hline Desired mover & 61.98 & 19.27 & 7.07 & 11.68 & 3,887 \\
\hline Total $(\%$ and $N)$ & 62.82 & 29.04 & 2.87 & 5.26 & 72,215 \\
\hline
\end{tabular}

Source: $B H P S$, author calculations

Pearson chi $^{2} p<0.001$ 
Table 3. Sequence groupings and classification rules ( $N=4,912$ individuals)

\begin{tabular}{|c|c|c|c|}
\hline Sequence group & $\mathbf{N}_{\mathrm{i}}(\%)$ & Rules for identification & Description \\
\hline Rooted & $\begin{array}{l}184 \\
(24.1)\end{array}$ & $\begin{array}{l}\text { 1) Never move } \\
\text { 2) Desire to move at fewer than } 4 \text { waves }\end{array}$ & $\begin{array}{l}\text { Rooted individuals have very stable biographies. They never move across } \\
\text { the period and rarely express a desire to relocate. When moving desires } \\
\text { are expressed, these are largely ephemeral. }\end{array}$ \\
\hline Wishful thinkers & $\begin{array}{l}754 \\
(15.4)\end{array}$ & $\begin{array}{l}\text { 1) Never move } \\
\text { 2) Desire to move in at least } 4 \text { waves } \\
\text { 3) Abandon } 3 \text { or fewer moving desires }\end{array}$ & $\begin{array}{l}\text { Wishful thinkers never move despite regularly and consistently expressing } \\
\text { a moving desire. Wishful thinkers rarely abandon their desire to move. }\end{array}$ \\
\hline Contented movers & $\begin{array}{l}891 \\
(18.1)\end{array}$ & $\begin{array}{l}\text { 1) Make up to } 3 \text { desired moves } \\
\text { 2) Make no undesired moves } \\
\text { 3) All moves are followed by a spell as a desired stayer }\end{array}$ & $\begin{array}{l}\text { These individuals make one or more desired moves, often after desiring to } \\
\text { move for many years. These moves relieve disequilibrium, as contented } \\
\text { movers always become desired stayers following relocation. }\end{array}$ \\
\hline $\begin{array}{l}\text { Discontented } \\
\text { movers }\end{array}$ & $\begin{array}{l}459 \\
(9.3)\end{array}$ & $\begin{array}{l}\text { 1) Make up to } 3 \text { (un)desired moves } \\
\text { 2) Abandon } 3 \text { or fewer moving desires } \\
\text { 3) No more than } 50 \% \text { of moves are followed by a spell as } \\
\text { a desired stayer }\end{array}$ & $\begin{array}{l}\text { Discontented movers are individuals for whom moving often fails to } \\
\text { satisfy their needs and preferences. These individuals frequently report } \\
\text { desiring to move again immediately after relocating. }\end{array}$ \\
\hline Adaptive movers & $\begin{array}{l}597 \\
(12.2)\end{array}$ & $\begin{array}{l}\text { 1) Make }>=1 \text { undesired moves and }<=3 \text { total moves } \\
\text { 2) Abandon } 3 \text { or fewer moving desires } \\
\text { 3) All undesired moves are followed by a spell as a } \\
\text { desired stayer }\end{array}$ & $\begin{array}{l}\text { These individuals differ from contented movers as they make at least one } \\
\text { undesired move. Adaptive movers do not seem disadvantaged by these } \\
\text { moves, as they always subsequently become a desired stayer. }\end{array}$ \\
\hline Oscillators & $\begin{array}{l}145 \\
(3.0)\end{array}$ & $\begin{array}{l}\text { 1) Abandon at least } 4 \text { moving desires } \\
\text { 2) Make fewer than } 3 \text { moves }\end{array}$ & $\begin{array}{l}\text { Oscillator sequences are characterised by the frequent expression and } \\
\text { abandonment of moving desires. }\end{array}$ \\
\hline Highly mobile & $\begin{array}{l}486 \\
(9.9)\end{array}$ & 1) Make at least 4 moves & $\begin{array}{l}\text { These sequences are characterised by frequent moves. Many highly } \\
\text { mobile individuals also report desiring to move for considerable periods } \\
\text { of time. }\end{array}$ \\
\hline Miscellaneous & $\begin{array}{l}396 \\
(8.1)\end{array}$ & $\begin{array}{l}\text { 1) Sequences which cannot be classified according to the } \\
\text { above rules }\end{array}$ & $\begin{array}{l}\text { Many of these sequences are unclassifiable due to truncation or because it } \\
\text { is difficult to evaluate the consequences of moves made in the final BHPS } \\
\text { sweep. Other sequences in this category are highly complex. }\end{array}$ \\
\hline
\end{tabular}


Table 4. Variable summary statistics ( $\mathrm{N}$ individuals=4,912)

\begin{tabular}{|c|c|c|}
\hline Categorical variables & Frequency & $\%$ \\
\hline \multicolumn{3}{|l|}{ Age of respondent in $1991(\mathrm{ref}=30-49)$} \\
\hline Under 30 & 1,412 & 28.75 \\
\hline $50-64$ & 1,088 & 22.15 \\
\hline Female dummy (ref=male) & 2,696 & 54.89 \\
\hline \multicolumn{3}{|l|}{ Partnership trajectory during mobility sequence (ref=stable couple) } \\
\hline Stable single & 426 & 8.67 \\
\hline Enter couple & 448 & 9.12 \\
\hline Exit couple & 325 & 6.62 \\
\hline Fluctuate between couple and single & 659 & 13.42 \\
\hline Incomplete trajectory & 595 & 12.11 \\
\hline \multicolumn{3}{|c|}{ Presence of dependent children in household during mobility sequence (ref=never present) } \\
\hline Always children & 461 & 9.39 \\
\hline No children-children & 548 & 11.16 \\
\hline Children-no children & 1,076 & 21.91 \\
\hline Fluctuate between children and no children & 590 & 12.01 \\
\hline Incomplete trajectory & 632 & 12.87 \\
\hline \multicolumn{3}{|l|}{ Modal education level during mobility sequence (ref=no qualifications) } \\
\hline Low (basic secondary school level-eg. GCSE) & 1,302 & 26.51 \\
\hline Medium (higher school or vocational qualifications-eg. A Level) & 1,885 & 38.38 \\
\hline High (university degree and above) & 637 & 12.97 \\
\hline Unknown & 34 & 0.69 \\
\hline \multicolumn{3}{|c|}{ Housing tenure trajectory during mobility sequence (ref=stable homeowner) } \\
\hline Stable renter (social or private) & 504 & 10.26 \\
\hline Enter ownership & 394 & 8.02 \\
\hline Exit ownership & 169 & 3.44 \\
\hline Fluctuate between renting and owning & 595 & 12.11 \\
\hline Incomplete trajectory & 348 & 7.08 \\
\hline Continuous variables & Mean & S.D. \\
\hline Log median household income during mobility sequence $^{1}$ & 10.00 & 0.50 \\
\hline Variance in $\log$ household income during mobility sequence ${ }^{1}$ & 0.21 & 0.39 \\
\hline
\end{tabular}

TAnnual household incomes were adjusted to 2005 values and deflated using the McClements Before Housing Costs equivalence scale, to take into account differences in household size and composition

Source: BHPS, author calculations 
Table 5. Six logit models estimating the likelihood of experiencing each sequence type (ref=contented mover)

\begin{tabular}{|c|c|c|c|c|c|c|c|c|c|c|c|c|}
\hline \multirow[t]{2}{*}{ Variable } & \multirow{2}{*}{$\begin{array}{l}\text { Rooted } \\
\text { Coeff. }\end{array}$} & \multicolumn{3}{|c|}{ Wishful } & \multicolumn{2}{|c|}{ Discontented } & \multicolumn{2}{|l|}{ Adaptive } & \multicolumn{2}{|l|}{ Oscillator } & \multicolumn{2}{|c|}{ Highly mobile } \\
\hline & & S.E. & Coeff. & S.E. & Coeff. & S.E. & Coeff. & S.E. & Coeff. & S.E. & Coeff. & S.E. \\
\hline \multicolumn{13}{|l|}{ Age in 1991 (ref 30-49) } \\
\hline$<30$ & $-1.022 * * *$ & 0.158 & $-0.868 * * *$ & 0.161 & 0.020 & 0.158 & 0.072 & 0.142 & $-0.627 * *$ & 0.292 & $0.730 * *$ & 0.223 \\
\hline $50-64$ & $0.371 * *$ & 0.142 & $-0.278^{*}$ & 0.160 & $-0.612 * *$ & 0.237 & -0.116 & 0.185 & 0.353 & 0.278 & $-1.087 * *$ & 0.410 \\
\hline Female & -0.017 & 0.102 & -0.120 & 0.111 & $-0.440 * *$ & 0.134 & -0.078 & 0.114 & -0.286 & 0.192 & -0.251 & 0.196 \\
\hline \multicolumn{13}{|c|}{ Partnership sequence (ref stable couple) ${ }^{1}$} \\
\hline Stable single & 0.082 & 0.176 & -0.047 & 0.201 & $0.589 * *$ & 0.251 & -0.027 & 0.223 & 0.265 & 0.340 & -0.075 & 0.425 \\
\hline Enter couple & $-1.220 * * *$ & 0.297 & $-0.741 * *$ & 0.280 & $0.917 * * *$ & 0.213 & $0.824 * * *$ & 0.187 & -0.254 & 0.454 & $1.090 * * *$ & 0.301 \\
\hline Exit couple & 0.125 & 0.215 & -0.058 & 0.246 & $0.690 * *$ & 0.272 & $0.644 * *$ & 0.224 & 0.392 & 0.354 & 0.384 & 0.441 \\
\hline Fluctuates & $-0.500 * *$ & 0.231 & -0.259 & 0.229 & $1.085^{* * *}$ & 0.215 & $0.694 * * *$ & 0.195 & -0.152 & 0.431 & $2.171 * * *$ & 0.275 \\
\hline \multicolumn{13}{|c|}{ Children sequence (ref never children) ${ }^{1}$} \\
\hline Always children & -0.313 & 0.196 & $-0.468 * *$ & 0.217 & 0.037 & 0.264 & -0.228 & 0.224 & 0.363 & 0.355 & -0.426 & 0.407 \\
\hline No children-children & $-1.270 * * *$ & 0.244 & $-0.857 * * *$ & 0.244 & 0.100 & 0.241 & -0.200 & 0.202 & $-1.810^{* *}$ & 0.762 & 0.063 & 0.335 \\
\hline Children-no children & 0.184 & 0.147 & 0.231 & 0.161 & 0.134 & 0.220 & 0.113 & 0.178 & $0.706^{* *}$ & 0.285 & 0.116 & 0.336 \\
\hline Fluctuates & 0.136 & 0.208 & 0.060 & 0.224 & $0.542 * *$ & 0.249 & 0.181 & 0.224 & $0.939 * *$ & 0.343 & $0.845 * *$ & 0.333 \\
\hline \multicolumn{13}{|l|}{ Modal education level (ref very low) } \\
\hline Low & 0.020 & 0.148 & -0.069 & 0.159 & -0.174 & 0.219 & -0.065 & 0.176 & $0.527 *$ & 0.284 & -0.098 & 0.322 \\
\hline Medium & -0.176 & 0.146 & -0.097 & 0.156 & 0.107 & 0.205 & -0.181 & 0.173 & 0.378 & 0.280 & -0.019 & 0.321 \\
\hline High & -0.122 & 0.203 & -0.191 & 0.225 & -0.037 & 0.274 & -0.100 & 0.226 & -0.098 & 0.434 & 0.420 & 0.389 \\
\hline Median log of household income & $-0.397 * *$ & 0.128 & $-0.894 * * *$ & 0.140 & -0.220 & 0.163 & -0.087 & 0.136 & $-0.506^{* *}$ & 0.239 & 0.086 & 0.229 \\
\hline Variance in log household income & 0.018 & 0.177 & -0.137 & 0.231 & $0.641 * *$ & 0.221 & 0.336 & 0.213 & 0.434 & 0.314 & $1.335 * * *$ & 0.323 \\
\hline \multicolumn{13}{|c|}{ Housing tenure sequence (ref stable owner) ${ }^{1}$} \\
\hline Stable renter & $-0.637 * * *$ & 0.184 & $-0.314 *$ & 0.186 & $0.622 * *$ & 0.233 & 0.301 & 0.204 & -0.512 & 0.341 & $1.910 * * *$ & 0.347 \\
\hline Enter ownership & $-1.136 * * *$ & 0.215 & $-0.515 * *$ & 0.208 & $0.553 * *$ & 0.204 & $0.328 *$ & 0.177 & $-0.808 * *$ & 0.409 & $1.190 * * *$ & 0.289 \\
\hline Exit ownership & $-3.732 * * *$ & 0.744 & $-2.978 * * *$ & 0.743 & $1.438 * * *$ & 0.286 & $0.534 *$ & 0.275 & -0.515 & 0.532 & $2.935 * * *$ & 0.389 \\
\hline Fluctuates & $-1.536 * * *$ & 0.417 & $-0.781 * *$ & 0.398 & $2.122 * * *$ & 0.245 & $1.208 * * *$ & 0.250 & -0.584 & 0.653 & $4.316 * * *$ & 0.290 \\
\hline Constant & $4.775 * * *$ & 1.306 & $9.397 * * *$ & 1.427 & 0.644 & 1.691 & 0.123 & 1.400 & 2.945 & 2.436 & $-4.662 *$ & 2.385 \\
\hline Loglikelihood & -1201.104 & & -997.775 & & -713.995 & & -941.447 & & -378.350 & & -384.718 & \\
\hline (improvement over null) & $(208.827)$ & & $(125.862)$ & & (147.167) & & $(51.756)$ & & $(40.364)$ & & $(502.953)$ & \\
\hline $\mathrm{Chi}^{2}$ (d.f.) & $417.655(23$ & & 251.724 & & 294.335 & & 103.511 & & $80.727(23)$ & & 1005.907 & \\
\hline Cox-Snell pseudo-r ${ }^{2}$ & 0.183 & & 0.143 & & 0.197 & & 0.068 & & 0.075 & & 0.521 & \\
\hline $\mathrm{N}$ & 2064 & & 1630 & & 1343 & & 1476 & & 1031 & & 1368 & \\
\hline
\end{tabular}

1 These variables also include categories for incomplete sequences (results not shown)

Source: BHPS, author calculations 
Figure 1. The mobility biographies of BHPS respondents

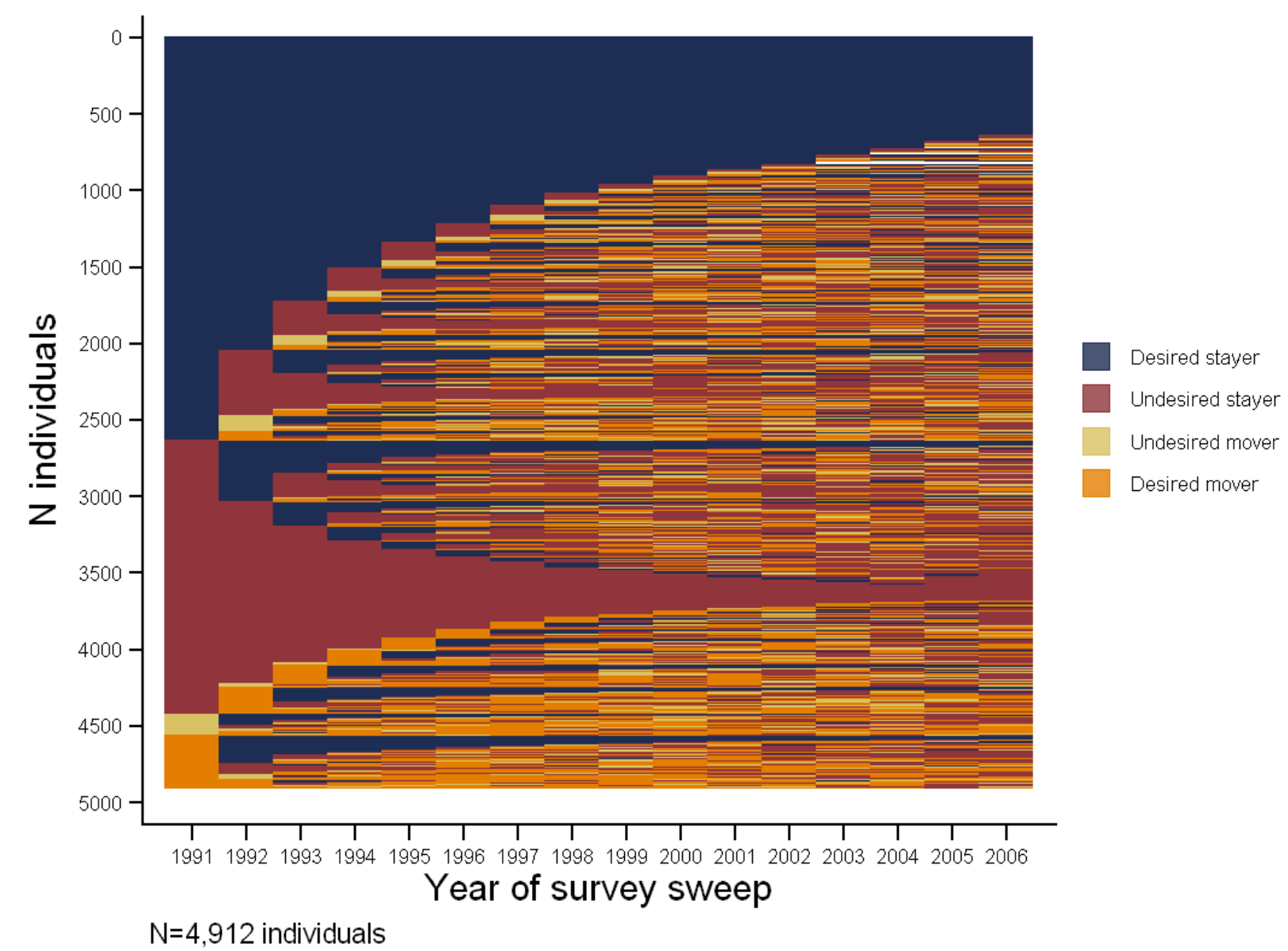

Source: BHPS 
Figure 2a. A typology of mobility biographies

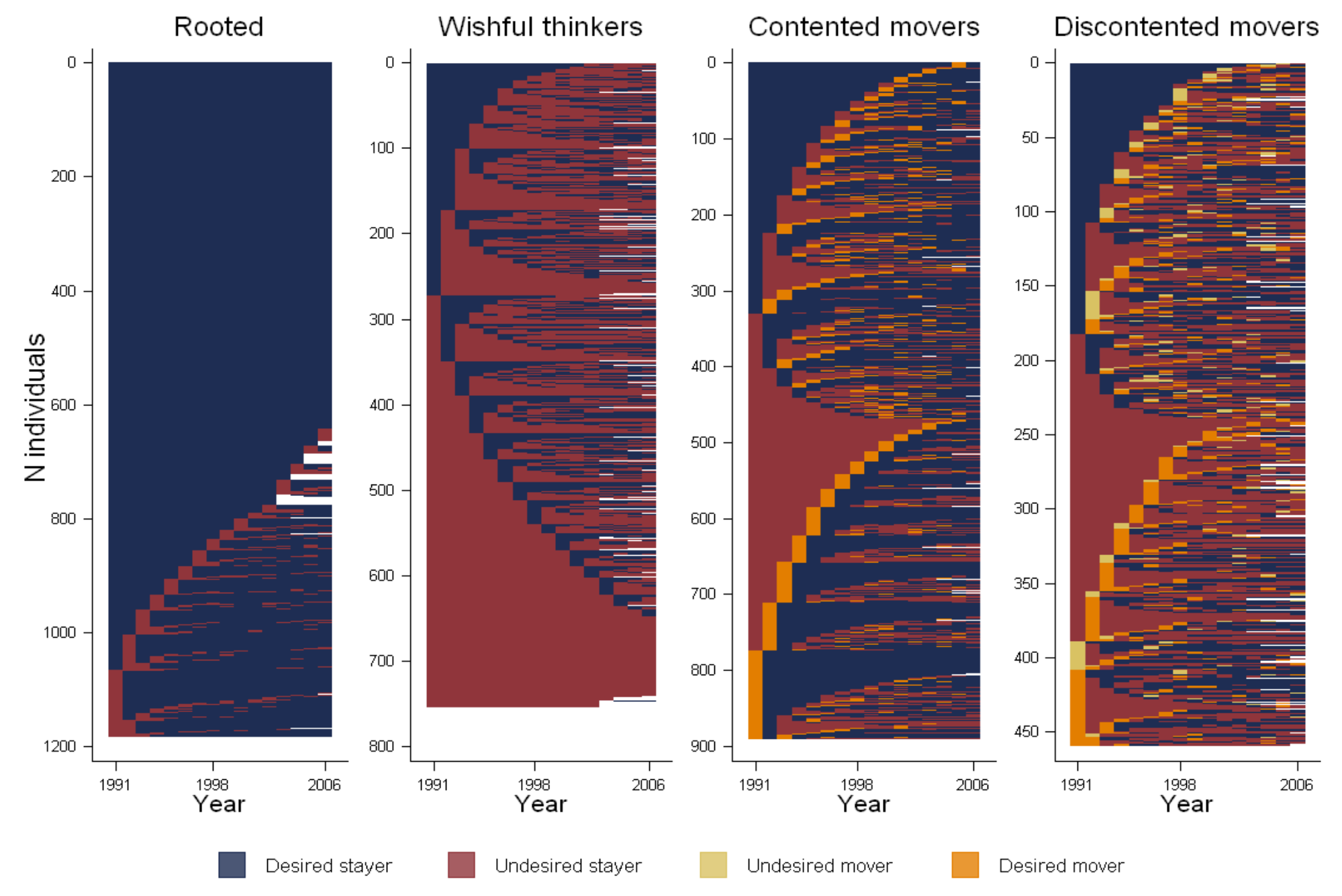

Source: BHPS 
Figure 2b. A typology of mobility biographies continued

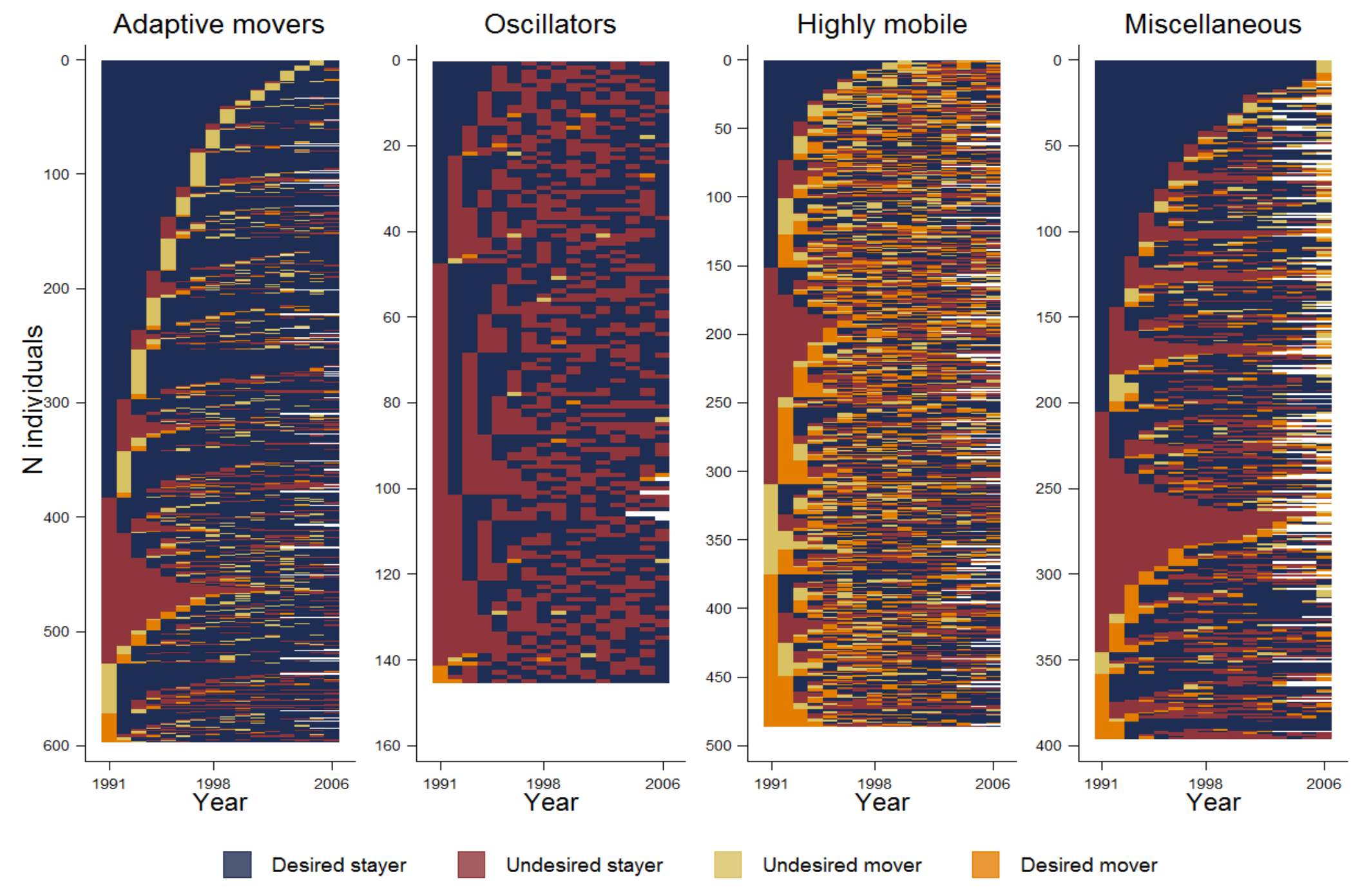

Source: BHPS 
Figure 3. The likelihood of experiencing each sequence type by age in 1991

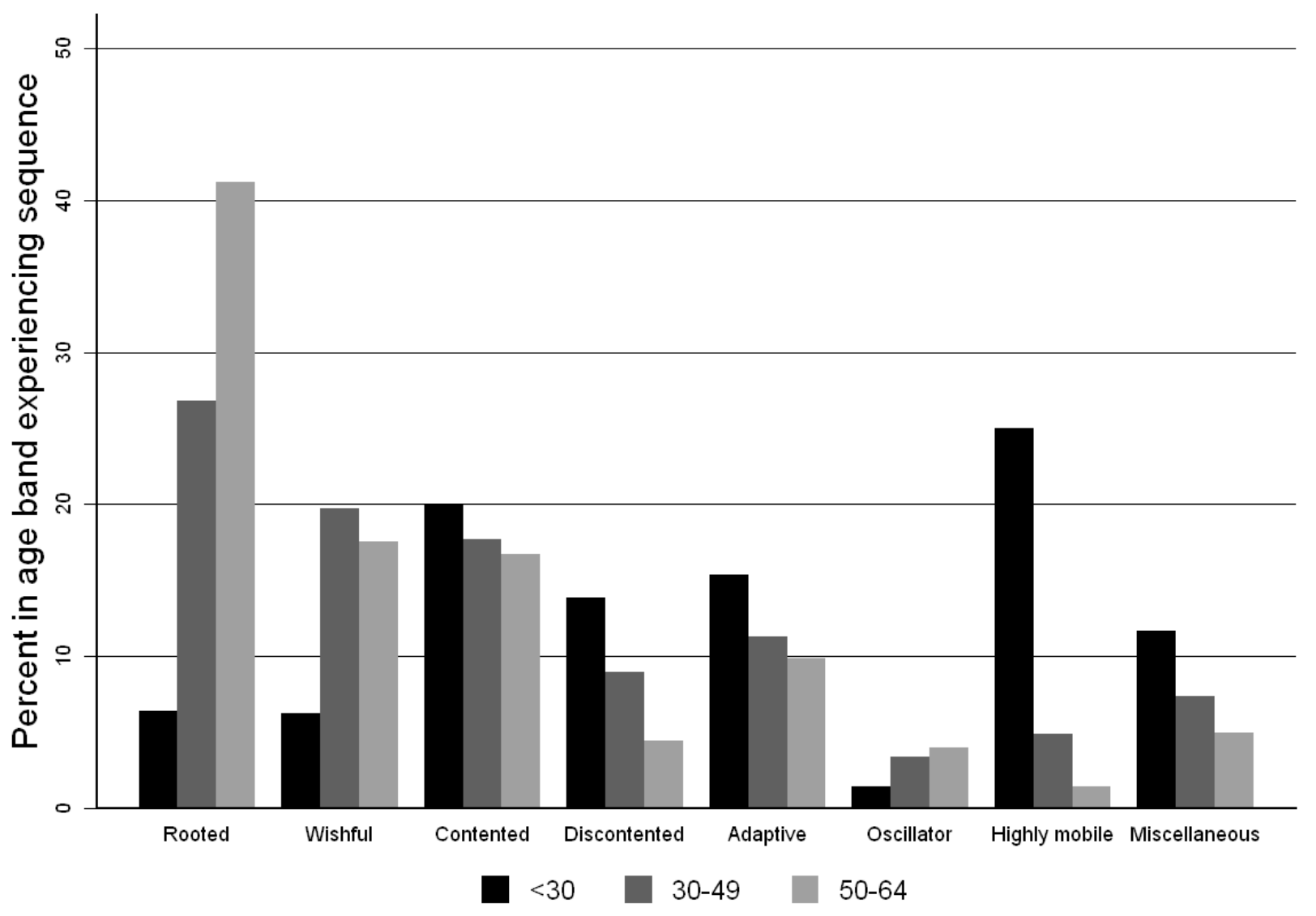

Source: BHPS, author calculations 